\title{
Sero-Prevalence of Hepatitis B Virus and Associated Factors Among Pregnant Mothers Attending Antenatal Care in Public Health Facilities, Dire Dawa
}

\section{Robel Mekonnen ${ }^{1 *}$, Dawit Admasu² and Meseret Belete ${ }^{1}$}

${ }^{1}$ School of Medicine, College of Medicine and Health Sciences, Dire Dawa university, Ethiopia

${ }^{2}$ Department of Medical Laboratory, College of Medicine and Health Sciences, Wachamo University, Ethiopia.

\begin{abstract}
Background: According to the WHO report, Ethiopia is regarded as a country with intermediate to hyperendemic viral hepatitis infections, though it has no national strategy for surveillance, prevention and control of viral hepatitis. Without intervention, a mother who is positive for $\mathrm{HBsAg}$ and $\mathrm{HBeAg}$ has as high as $90 \%$ risk of passing the infection to her offspring. Therefore, this study tried to assess the seroprevalence and associated factors of HBV infection among pregnant women attending antenatal care in public health facilities of Dire-Dawa, Eastern Ethiopia.

Materials and methods: A facility based cross-sectional study was conducted from January to March 2018 among 334 pregnant mothers. After obtaining a consent forms, data were collected by face to face interview and blood samples were collected to test for HBsAg. Logistic regression analysis was employed to identify factors significantly associated with HBV infection. A p value $<0.05$ was considered as level of significance.

Results: The mean age of participated pregnant mothers was 24.93 years (+2 SD 5.21). The prevalence of HBV infection found to be $8.4 \%$ in the study area. On multivariate analysis, being single pregnant mothers (p-0.002), having nose/ear pierce (p-0.018), history of blood transfusion (p-0.008), circumcision (p-0.004), and HIV coinfection (p-0.032) $\}$ were factors significantly associated with HBV infection.

Conclusion: To halt spread of this virus, increasing awareness on modes of transmission should be considered. Screening all pregnant women for HBV should be made as part of routine antenatal care service. Interventions should be targeted on reduction of circumcision by all concerned bodies.
\end{abstract}

Keywords: HBV infection; HBsAg; Risk factors; Pregnant mother; Dire Dawa

\section{Introduction}

The name "Hepatitis" is derived from the combination of two Greek words "hepatos" (liver) and "itis" (inflammation) which is a disease of the liver usually caused by viral infections [1]. Five different types of hepatitis viruses (A-E) are responsible for causing viral hepatitis [2]. Hepatitis $B$ virus (HBV) is one of these viruses and belong to member of the Hepadnaviridae family which is enveloped partially doublestranded DNA virus [3].

HBV has numerous antigenic components such as Hepatitis B surface antigen (HBsAg), Hepatitis B core antigen (HBcAg), and Hepatitis B envelope antigen ( $\mathrm{HBeAg}$ ) [4]. HBsAg persisting for a period exceeding six months is defined as chronic HBV infection [5]. The virus has a high rate of vertical transmission, causing congenital infection among babies born to infected mothers as well as a major blood-borne and sexually transmitted infectious agent $[1,6]$.

HBV infection is one of the major public health problems in the world $[7,8]$. Global estimate indicates that 240 million people are chronically infected with HBV and the largest number of people living with chronic HBV live in the Western Pacific region (over 95 million) followed by the African region (over 75 million) [9,10]. Africa is considered as a region of high endemicity and has prevalence of HBV of $>8 \%$. Reports also demonstrated that 68,600 people die of $\mathrm{HBV}$ infection and more than 300,000 deaths due to liver cancer secondary to hepatitis B every year globally $[11,12]$.

Acute HBV carries a risk both for the mother and the newborn [13]. When the infection is acquired during the perinatal period, the risk of becoming a chronic infection carrier is $95 \%$ which is high compared to those acquired during adulthood which is only $5 \%$. Vertical transmission rate reaches approximately $90 \%$ when women are seropositive for both HBsAg and HBeAg [14,15]. Fetal and neonatal hepatitis acquired from mother during pregnancy lead to impaired cognitive and physical development in later life of the children $[1,16]$.

According to the WHO report, Ethiopia is regarded as a country with intermediate to hyperendemic viral hepatitis infections, though it has no national strategy for surveillance, prevention and control of viral hepatitis $[13,17]$. It was estimated that over 5 million people are living with chronic $\mathrm{HBV}$ infection among the general population of Ethiopia [10]. Few studies conducted in Ethiopia at different study area and period reported high prevalence rate of HBV infection among pregnant mothers. For instance, a prevalence of $8.1 \%$ was reported in Mekelle 2015, 4.9\% in Dessei 2014, 5.4\% in Bishoftu General Hospital at 2016, and 6.9\% in Deder Hospital, Eastern Ethiopia, 2016 [18-21]. Despite the problem, routine HBV screening of pregnant women is not given as routine antenatal care (ANC) service in most health facilities

*Corresponding author: Robel Mekonnen, School of Medicine, College of Medicine and Health Sciences, Dire Dawa university, Ethiopia, Tel: +251913 2780 09; E-mail: robelmekonnen@gmail.com

Received July 25, 2018; Accepted August 06, 2018; Published August 11, 2018

Citation: Mekonnen R, Admasu D, Belete M (2018) Sero-Prevalence of Hepatitis B Virus and Associated Factors Among Pregnant Mothers Attending Antenatal Care in Public Health Facilities, Dire Dawa. J Med Microb Diagn 7: 281. doi:10.4172/21610703.1000281

Copyright: $\odot 2018$ Mekonnen R, et al. This is an open-access article distributed under the terms of the Creative Commons Attribution License, which permits unrestricted use, distribution, and reproduction in any medium, provided the original author and source are credited. 
of Ethiopia [22]. In Dire-Dawa, Eastern Ethiopia, the magnitude and burden of HBV infection among pregnant women is not known and there is no locally generated information about associated factors of the infection. Therefore, this study tried to assess the sero-prevalence of $\mathrm{HBV}$ infection and associated risk factors among pregnant women attended at public health facilities of Dire Dawa Administration.

\section{Materials and Methods}

\section{Study area}

This study was conducted in public health facilities found in Dire Dawa Administration. Dire Dawa is in the eastern part of Ethiopia about $515 \mathrm{~km}$ away from capital Addis Ababa. It lies with a latitude and longitude of $9^{\circ} 36^{\prime} \mathrm{N}, 41^{\circ} 52^{\prime} \mathrm{E}$. Based on the 2007 Census conducted by the Central Statistical Agency of Ethiopia (CSA), Dire Dawa has total population of 342,827 consisted of 171,930 men and 170,897 women. About $69.92 \%$ of the population are considered urban inhabitants, with an estimated area of 1,231.20 square kilometers [23]. The Administration has two public hospital, fifteen health centers and thirty-four health posts; all consisting of 307 units/departments (i.e., 253 units in health center, 23 units in hospital and 34 health posts) [24]. Determination of hemoglobin level, urine analysis, blood group and syphilis screening are given for pregnant women as routine ANC follow-up by all hospitals and health centers, but screening of HBV infection is not practiced in most health facilities found in DireDawa [25].

\section{Study design and period}

Facility based cross-sectional study design was employed to determine the sero-prevalence of HBV infection among pregnant mothers in Dire-Dawa health facilities between January to March 2018.

\section{Sample size determination}

The total sample size of pregnant women for the study was calculated based on single proportion formula by taking the highest prevalence of HBV infection (8.1\%) among pregnant women from a study in Mekelle, $3 \%$ (0.03) expected margin of error (d) and $95 \%$ confidence interval [18].

$$
\begin{aligned}
& n=\frac{\left(Z_{a / 2}\right)^{2} * p(1-p)}{d^{2}} \\
& n=318
\end{aligned}
$$

Adding 5\% non-response rate, which is 16 , the final sample size was 334 .

\section{Sampling technique}

First five public health facilities found in Dire-Dawa Administration were selected by lottery methods. Then the total sample size of pregnant mothers was allocated for each facility proportional to their population size. Finally participated pregnant mothers attending ANC clinic at the time of data collection were select using systematic random sampling method.

\section{Data collection methods}

A face to face interview using pre-tested structured questionnaires was administered among 334 pregnant women at the end of their ANC follow-up. Six Clinical nurses were assigned as an interviewer. The questionnaire was adopted from similar study done in Dessei and modified based on the specific objectives of this study [19]. This questionnaire provides detailed information on socio-demographic, behavioral and clinical variables useful for this study. To ensure consistency, the English version of the questionnaire was translated to local language and then back to English by language experts. After obtaining written consent forms from the study participants, data was collected from January to March 2018.

\section{Specimen collection and processing}

About $5 \mathrm{ml}$ of venous blood was collected from each participant. Individual blood samples were given unique patient code for easy identification and then transferred to a clean, sterile plain test tube and allowed to clot naturally. After clotting, serum was extracted from each sample by centrifugation at $5000 \mathrm{rpm}$ for 15 minutes and the sera was further isolated using micropipette in to another, sterile plain test tube and stored at $-20^{\circ} \mathrm{C}$ until laboratory analysis. All serum was tested for HBsAg using Enzyme-Linked Immunosorbent Assay (ELISA) (Dialab $\mathrm{GmbH}$, Wiener Neudorf, Austria) based on following manufacturer's instructions [20].

\section{Data quality control}

Assigned data collectors were trained health professionals (clinical nurse) who had at least one-year work experience. Then two days training was given for interviewers and blood sample collectors. Another two days orientation was also given to laboratory professionals about sample processing and analysis. Before the start of data collection, pretest was done on $5 \%$ of the sample size in health center not included in this study. Two senior laboratory technologists were assigned for each selected Hospitals and Health Centers as supervisors. The principal investigator made daily checkup and monitor the quality of the data and sample collection and analysis procedures.

\section{Data analysis}

After checking for completeness, the collected data were first entered and cleaned using EpI data version 3.1 and exported to statistical packaging for social science (SPSS, version 20) for further analysis. Data were analyzed using descriptive statistics and presented by tables and figure. Bivariate analysis was used to evaluate the association between the independent and the outcome variable. Adjusted odd ratio along with $95 \%$ CI was employed to identify significant factors associated with HBV infection in multivariable logistic regression analysis. Level of statistical significance was declared at $\mathrm{p}<0.05$

\section{Results}

\section{Socio-demographic characteristics of study participants}

A total of 334 pregnant mothers attending ANC service in selected public health facilities of Dire Dawa Administration were participated with response rate of $100 \%$. The mean age was $24.93(5.21+2$ SD) with the minimum and maximum age of 16 and 43 years, respectively.

As displayed in Table 1 below, majority 142(42.5\%) of pregnant mothers were in the age group of 25 to 30 years and only $7(2.1 \%)$ were in the age of forty years and above. About 259(77.5\%) were urban dwellers, 64(19.2\%) were illiterate and only 91(27.2\%) had Diploma and above. Regarding marital status and occupation of the study participants, majority $291(87.1 \%)$ are married, 206(61.7\%) are housewife and only $52(15.6 \%)$ had office work.

\section{Prevalence of HBV infection relation to risky health behavior and past medical history}

As displayed in Figure 1 below out of 334 study participants, sero positivity for HBsAg was detected among 28 pregnant mothers, making the overall prevalence of HBV infections $8.4 \%$. 
As shown in Table 2 below about 6(6.1\%), 5(15.6\%) and 10(13.7\%) of HBV infection detected among pregnant mothers who had habit of chewing Khat, smoking and drinking alcohols, respectively. Similarly, $5(23.8 \%)$ of the infected pregnant mothers responded they had experienced multiple sexual practice. About 6(14.3\%) and 9(23.7\%) HBV infection was also detected among pregnant mothers who had tattoo and nose/ear pierce, respectively. Out of 33 participated pregnant mothers who had history of surgery, 6(18.2\%) of them found infected. Similarly, from the total of 20 pregnant mothers with history of blood transfusion and/or donation $6(30.0 \%)$ were infected, while $10 / 65(15.4 \%), 16 / 115(13.9 \%)$ and 4/28(14.3\%) pregnant mothers who had history of abortion, circumcision and dental procedures were also found infected with HBV, respectively. On the other hand, a total of 17(5.1\%) pregnant mothers were found HIV positive, and HBV was detected among $8(47.1 \%)$. So, the HIV/HBV co-infection found to be $47.1 \%$ (Table 3 ).

\section{Bivariate and multivariate analysis of possible factors of $\mathrm{HBV}$ infection}

On the bivariate analysis, single pregnant mothers, those who had experienced multiple sexual practice, pregnant mothers having nose/ ear piercing, previous surgery, history of blood transfusion, history of abortion, circumcision and HIV co-infection showed significant association with sero-positivity of HBsAg $(\mathrm{p}<0.05)$. However, when these variables were adjusted in multivariate analysis, being single pregnant mothers AAOR (8.5), 95\% CI $(2.23,33.04)$; p-value (0.002)\}, having nose/ear piercing AOR (3.8), 95\% CI (1.25, 11.79); p-value $(0.018)\}$, history of blood transfusion $\{$ AOR $(6.5), 95 \%$ CI $(1.65,26.10)$; p-value (.008)\}, circumcision $\{$ AOR (4.4), 95\% CI (1.59, 12.15); p-value (0.004)\}, and HIV co-infection \{AOR (4.1), 95\% CI (1.13, 15.09); p-value (0.032)\} had statistically significant association with positivity of HBV infection (Table 4).

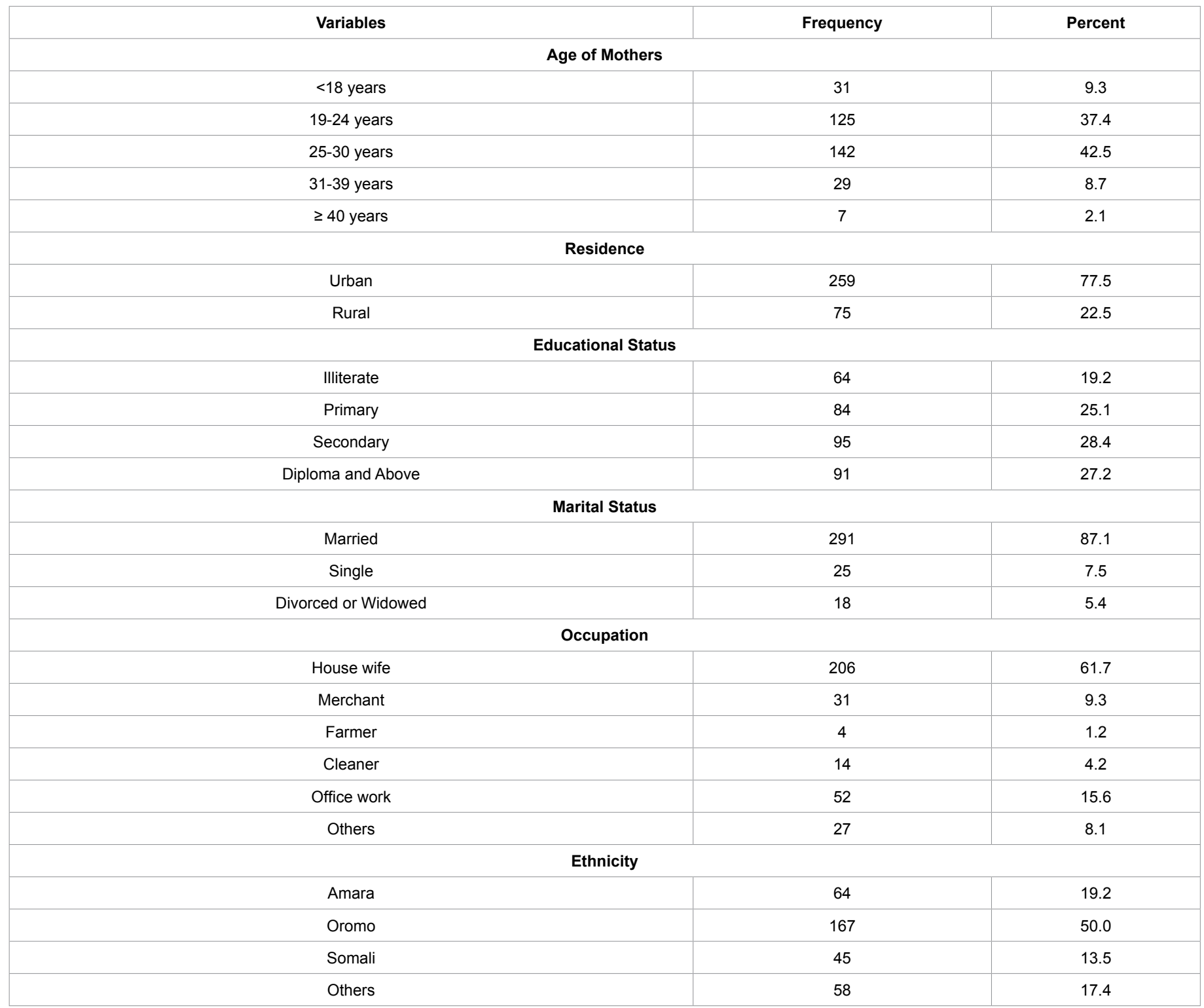

Table 1: Demographic characteristics of pregnant mothers attending ANC service in public health facilities in Dire Dawa, Eastern Ethiopia ( $n=334$ ). 


\begin{tabular}{|c|c|c|c|}
\hline \multirow{2}{*}{ Variables } & \multicolumn{3}{|c|}{ HBsAg Test Status } \\
\hline & Positive N (\%) & Negative N (\%) & Total \\
\hline \multicolumn{4}{|c|}{ Khat Chewing } \\
\hline Yes & $6(6.1 \%)$ & $92(93.9 \%)$ & $98(29.3 \%)$ \\
\hline No & $22(9.3 \%)$ & $214(90.7 \%)$ & $236(70.7 \%)$ \\
\hline \multicolumn{4}{|c|}{ Smoking Cigarette/Shisha } \\
\hline Yes & $5(15.6 \%)$ & $27(84.4 \%)$ & $32(9.6 \%)$ \\
\hline No & $23(7.6 \%)$ & $279(92.4 \%)$ & $302(90.4 \%)$ \\
\hline \multicolumn{4}{|c|}{ Drinking Alcohols } \\
\hline Yes & $10(13.7 \%)$ & $63(86.3 \%)$ & $73(21.9 \%)$ \\
\hline No & $18(6.9 \%)$ & $243(93.1 \%)$ & $261(78.1 \%)$ \\
\hline \multicolumn{4}{|c|}{ Have Multiple Sexual Partners } \\
\hline Yes & $5(23.8 \%)$ & $16(76.2 \%)$ & $21(6.3 \%)$ \\
\hline No & $23(7.3 \%)$ & $290(92.7 \%)$ & $313(93.7 \%)$ \\
\hline \multicolumn{4}{|c|}{ Tattooing } \\
\hline Yes & $6(14.3 \%)$ & $36(85.7 \%)$ & $42(12.6 \%)$ \\
\hline No & $22(7.5 \%)$ & $270(92.5 \%)$ & $292(87.4 \%)$ \\
\hline \multicolumn{4}{|c|}{ Nose/Ear Piercing } \\
\hline Yes & $9(23.7 \%)$ & $29(76.3 \%)$ & $38(11.4 \%)$ \\
\hline No & $19(6.4 \%)$ & $277(93.6 \%)$ & $296(88.6 \%)$ \\
\hline \multicolumn{4}{|c|}{ Sharing of Needles } \\
\hline Yes & $1(14.3 \%)$ & $6(85.7 \%)$ & $7(2.1 \%)$ \\
\hline No & $27(8.3 \%)$ & $300(91.7 \%)$ & $327(97.9 \%)$ \\
\hline
\end{tabular}

Table 2: Prevalence of HBV infection relation with substance use and risky behaviours of pregnant mothers attending ANC service in public health facilities in Dire Dawa, Eastern Ethiopia $(n=334)$.

\section{Discussion}

Studies in our country and around the world recommended that pregnant women should be screened for HBV. This is because identifying the infection status of the mother is not only important for herself but also important for her baby to halt the transmission of the virus and the complications resulted by the virus [26].

The prevalence of chronic HBV infection varies greatly in different part of the world. According to WHO classification, the world-wide prevalence of chronic HBV infection can range from high $>8 \%$ (as in most resource-limited settings), intermediate when the prevalence is between $2 \%$ to $8 \%$ and low when $<2 \%$ (as in most developed settings) $[27,28]$.

The finding of this study revealed that the sero-prevalence of HBV infection among participated pregnant mothers in the study area was $8.4 \%$ which is higher than reported prevalence of $5.4 \%$ in study conducted in Bishoftu General Hospital, 6.9\% in Deder Hospital, Eastern Ethiopia, 4.9\% in Dessei [19-21]. But this study finding was nearly similar with reported prevalence of $7.8 \%$ in Hawassa, $8.1 \%$ in Mekele, 7.7\% in Cameroon 2013, 8.0\% in Mali 2012 and 9.3\% in Nigeria 2011 [29-32]. On the other hand, it was lower compared with the reported prevalence of $12.3 \%$ in Nigeria 2008 and $10.8 \%$ in Yemen 2008 [33,34]. The observed discrepancies in the magnitude of HBV prevalence across different geographical location might be attributed by variation in socio-demographic characteristics of the study population such as socio-cultural environment, tribal practices, traditional operation, sexual practices and medical exposure and the difference in hepatitis epidemiology. Moreover, the variation might be due to geographical situation, methodological difference, the level of awareness, cultural and behavioral differences for the potential risk factors of $\mathrm{HBV}$ infection.

The findings of the researches done in Ethiopia and other Africa countries indicated the presence of different factors contributing HBV infection in pregnant mothers. The present study revealed that except marital status, none of the other socio-demographic variables were significantly associated with HBV infection. Accordingly, single pregnant mothers were 8.5 times more likely to be infected with HBV than married pregnant mothers AOR (8.5), 95\% CI (2.23, 33.04); $\mathrm{p}$-value (0.002)\}. One possible explanation might be having more than one sexual partner that put single mothers at higher risk for sexually transmitted infections like HBV. Other justification for the observed high prevalence of HBV positivity among single pregnant mothers could be defined with the high probability of exposure for high risk health behavior [35].

This study also revealed that the probability of acquiring HBV infection was higher among pregnant mothers with history of nose/ ear pierce and this was statistically significant. The odd of having the infection was 4(3.8) times more likely higher among pregnant mothers who had nose/ear piercing AAOR $(3.8), 95 \%$ CI $(1.25,11.79)$; p-value $(0.018)\}$. This was in line with similar study conducted in Deder hospital (AOR 9.1; 95\% CI: 1.34-61.79) [21] and in Shashemene 
Citation: Mekonnen R, Admasu D, Belete M (2018) Sero-Prevalence of Hepatitis B Virus and Associated Factors Among Pregnant Mothers Attending Antenatal Care in Public Health Facilities, Dire Dawa. J Med Microb Diagn 7: 281. doi:10.4172/2161-0703.1000281

Page 5 of 8

\begin{tabular}{|c|c|c|c|}
\hline \multirow{2}{*}{ Variables } & \multicolumn{3}{|c|}{ HBsAg Test Status } \\
\hline & Positive N (\%) & Negative N (\%) & Total \\
\hline \multicolumn{4}{|c|}{ Stage of Pregnancy } \\
\hline First TM & $19(9.3 \%)$ & $186(90.7 \%)$ & $205(61.4 \%)$ \\
\hline Second TM & $4(5.2 \%)$ & $73(94.8 \%)$ & $77(23.1 \%)$ \\
\hline Third TM & $5(9.6 \%)$ & $47(90.4 \%)$ & $52(15.6 \%)$ \\
\hline \multicolumn{4}{|c|}{ History of Surgical Procedures } \\
\hline Yes & $6(18.2 \%)$ & $27(81.8 \%)$ & $33(9.9 \%)$ \\
\hline No & $22(7.3 \%)$ & $279(92.7 \%)$ & $301(90.1 \%)$ \\
\hline \multicolumn{4}{|c|}{ History of Home Delivery } \\
\hline Yes & $7(13.7 \%)$ & $44(86.3 \%)$ & $51(15.3 \%)$ \\
\hline No & $21(7.4 \%)$ & $262(92.6 \%)$ & $283(84.7 \%)$ \\
\hline \multicolumn{4}{|c|}{ Blood Transfusion or Donation } \\
\hline Yes & $6(30.0 \%)$ & $14(70.0 \%)$ & $20(6.0 \%)$ \\
\hline No & $22(7.0 \%)$ & $292(93.0 \%)$ & $314(94.0 \%)$ \\
\hline \multicolumn{4}{|c|}{ History of Abortion } \\
\hline Yes & $10(15.4 \%)$ & $55(84.6 \%)$ & $65(19.5 \%)$ \\
\hline No & $18(6.7 \%)$ & $251(93.3 \%)$ & $269(90.5 \%)$ \\
\hline \multicolumn{4}{|c|}{ History of Circumcision } \\
\hline Yes & $16(13.9 \%)$ & $99(86.1 \%)$ & $115(34.4 \%)$ \\
\hline No & $12(5.5 \%)$ & $207(94.5 \%)$ & $219(65.6 \%)$ \\
\hline \multicolumn{4}{|c|}{ History of Dental Procedure } \\
\hline Yes & $4(14.3 \%)$ & $24(85.7 \%)$ & $28(8.4 \%)$ \\
\hline No & $24(7.8 \%)$ & $282(92.2 \%)$ & $306(91.6 \%)$ \\
\hline \multicolumn{4}{|c|}{ HIV Positivity status } \\
\hline Yes & $8(47.1 \%)$ & $9(52.9 \%)$ & $17(5.1 \%)$ \\
\hline No & $20(6.3 \%)$ & $297(93.7 \%)$ & $317(94.9 \%)$ \\
\hline \multicolumn{4}{|c|}{ History of Hospitalization } \\
\hline Yes & $5(4.9 \%)$ & $98(95.1 \%)$ & $103(30.8 \%)$ \\
\hline No & $23(10.0 \%)$ & $208(90.0 \%)$ & $231(69.2 \%)$ \\
\hline
\end{tabular}

Table 3: Prevalence of HBV infection and medical history of pregnant mothers attending ANC in public health facilities in Dire Dawa, Eastern Ethiopia ( $n=334$ ).

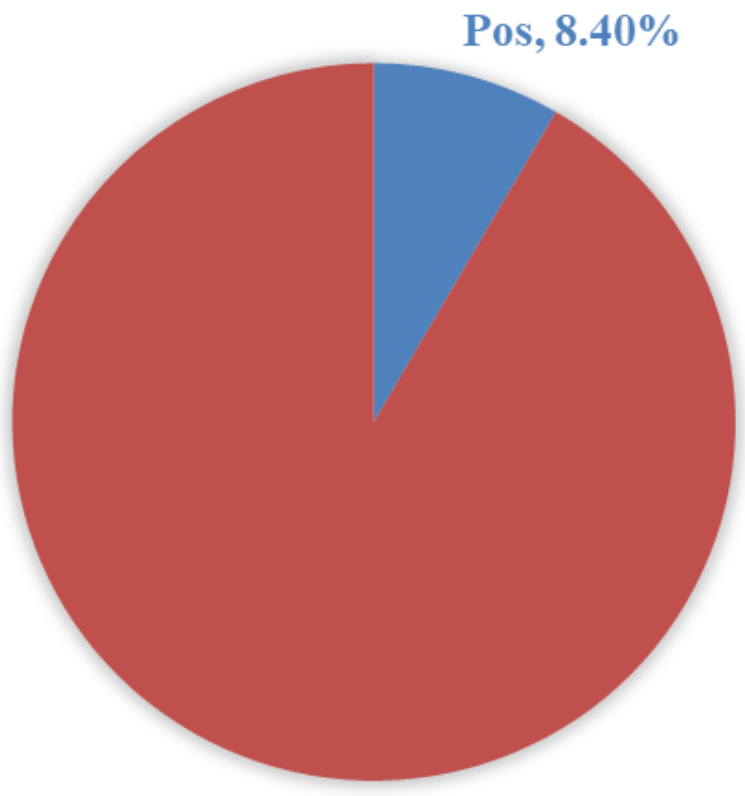

Neg, $91.60 \%$

Figure 1: HBV seroprevalence of pregnant mothers attending ANC service in public health facilities in Dire Dawa, Eastern Ethiopia ( $n=334$ ) 
Citation: Mekonnen R, Admasu D, Belete M (2018) Sero-Prevalence of Hepatitis B Virus and Associated Factors Among Pregnant Mothers Attending Antenatal Care in Public Health Facilities, Dire Dawa. J Med Microb Diagn 7: 281. doi:10.4172/2161-0703.1000281

Page 6 of 8

\begin{tabular}{|c|c|c|c|c|c|c|}
\hline \multirow{2}{*}{\multicolumn{2}{|c|}{ Variables }} & \multicolumn{2}{|c|}{ HBsAg Test Result } & \multirow{3}{*}{$\begin{array}{c}\text { COR }(95 \% \mathrm{Cl}) \\
1^{\mathrm{R}}\end{array}$} & \multirow{3}{*}{$\begin{array}{c}\text { AOR }(95 \% \mathrm{Cl}) \\
1^{R}\end{array}$} & \multirow{3}{*}{$\begin{array}{c}\text { p-value } \\
--\end{array}$} \\
\hline & & \multirow{2}{*}{$\begin{array}{l}\text { Pos (\%) } \\
20(6.9 \%)\end{array}$} & \multirow{2}{*}{$\begin{array}{c}\operatorname{Neg}(\%) \\
271(93.1 \%)\end{array}$} & & & \\
\hline \multirow{3}{*}{ Marital Status } & Married & & & & & \\
\hline & Single & $6(24.0 \%)$ & $19(76.0 \%)$ & $4.3(1.54,11.91)$ & $8.5(2.23,33.04)$ & 0.002 \\
\hline & Divorced or Widowed & $2(11.1 \%)$ & $16(88.9 \%)$ & $1.7(0.36,7.89)$ & $4.3(0.79,23.83)$ & 0.092 \\
\hline \multirow{3}{*}{ Stages of Pregnancy } & First TM & $19(9.3 \%)$ & $186(90.7 \%)$ & $0.96(0.34,2.70)$ & -- & -- \\
\hline & Second TM & $4(5.2 \%)$ & $73(94.8 \%)$ & $0.51(0.13,2.02)$ & -- & -- \\
\hline & Third TM & $5(9.6 \%)$ & $47(90.4 \%)$ & $1^{R}$ & -- & -- \\
\hline \multirow{2}{*}{ Multiple Sexual Partner } & Yes & $5(23.8 \%)$ & $16(76.2 \%)$ & $3.9(1.32,11.72)$ & $3.8(0.98,15.17)$ & 0.053 \\
\hline & No & $23(7.3 \%)$ & $290(92.7 \%)$ & $1^{R}$ & $1^{R}$ & -- \\
\hline \multirow{2}{*}{ Tattooing } & Yes & $6(14.3 \%)$ & $36(85.7 \%)$ & $2.0(0.78,5.38)$ & $1.3(0.39,4.43)$ & 0.658 \\
\hline & No & $22(7.5 \%)$ & $270(92.5 \%)$ & $1^{R}$ & $1^{R}$ & -- \\
\hline \multirow{2}{*}{ Nose/Ear Piercing } & Yes & $9(23.7 \%)$ & $29(76.3 \%)$ & $4.5(1.88,10.91)$ & $3.8(1.25,11.79)$ & 0.018 \\
\hline & No & $19(6.4 \%)$ & $277(93.6 \%)$ & $1^{R}$ & $1^{R}$ & -- \\
\hline \multirow{2}{*}{ Sharing of needles } & Yes & $1(14.3 \%)$ & $6(85.7 \%)$ & $1.8(0.21,15.95)$ & $4.4(0.36,54.15)$ & 0.245 \\
\hline & No & $27(8.3 \%)$ & $300(91.7 \%)$ & $1^{R}$ & $1^{R}$ & -- \\
\hline \multirow{2}{*}{ Surgical Procedures } & Yes & $6(18.2 \%)$ & $27(81.8 \%)$ & $2.8(1.05,7.55)$ & $2.3(0.68,7.80)$ & 0.177 \\
\hline & No & $22(7.3 \%)$ & $279(92.7 \%)$ & $1^{R}$ & $1^{R}$ & -- \\
\hline \multirow{2}{*}{$\begin{array}{l}\text { History of Blood } \\
\text { Transfusion }\end{array}$} & Yes & $6(30.0 \%)$ & $14(70.0 \%)$ & $5.7(1.99,16.25)$ & $6.5(1.65,26.10)$ & 0.008 \\
\hline & No & $22(7.0 \%)$ & $292(93.0 \%)$ & $1^{R}$ & $1^{R}$ & -- \\
\hline \multirow{2}{*}{ History of Abortion } & Yes & $10(15.4 \%)$ & $55(84.6 \%)$ & $2.5(1.11,5.79)$ & $2.7(0.94,7.58)$ & 0.066 \\
\hline & No & $18(6.7 \%)$ & $251(93.3 \%)$ & $1^{R}$ & $1^{R}$ & -- \\
\hline \multirow{2}{*}{ History of Circumcision } & Yes & $16(13.9 \%)$ & $99(86.1 \%)$ & $2.8(1.27,6.12)^{\star}$ & $4.4(1.59,12.15)$ & 0.004 \\
\hline & No & $12(5.5 \%)$ & $207(94.5 \%)$ & $1^{R}$ & $1^{R}$ & -- \\
\hline \multirow{2}{*}{ HIV Status } & Yes & $8(47.1 \%)$ & $9(52.9 \%)$ & $13.2(4.6,37.89)$ & $4.1(1.13,15.09)$ & 0.032 \\
\hline & No & $20(6.3 \%)$ & $297(93.7 \%)$ & $1^{R}$ & $1^{R}$ & -- \\
\hline
\end{tabular}

Table 4: Bivariate and multivariate analysis of possible risk factors of HBV infection among pregnant mothers in public health facilities in Dire Dawa, Eastern Ethiopia $(n=334)$.

[36]. The observed association might be due to sharing of infected needles during ear/nose piercing among households or neighborhood. Although high (18.2\%) HBV infection was detected among 33 pregnant mothers who had history of surgical procedure, statistically significant association was not observed with HBV infection; in contrast with the study findings in Deder hospital and in public hospitals, Ethiopia [21,37]. But it agreed with the study done in Egypt 2010 [38].

Transfusion-transmissible infectious agents such as HBV, HCV, HIV and syphilis are among the greatest threats to blood safety for transfusion recipients and pose a serious public health problem. The current study revealed that out of the total 20 pregnant mothers who had history of blood transfusion, 6 (30\%) were infected with HBV and this was significantly associated. Accordingly, pregnant mothers with history of blood transfusion were 6.5 more likely infected than those with no history of blood transfusion \{AOR $(6.5), 95 \%$ CI $(1.65,26.10)$; $\mathrm{p}$-value (0.008)\}. A similar picture was observed in previous studies conducted in Pakistan 2010, in Kano State of Nigeria 2012 and Egypt 2013 [39-41]. One possible justification could be contamination arise from HCWs itself or failure in following aseptic procedure during transfusion at health facility level or transfusion of HBV infected blood due to failure of screening of the donated blood at testing sites. In the present study we noticed higher number 115/334 (34.4\%) of participated pregnant women had history of circumcision. Out of these mothers 16 (13.9\%) were infected with HBV and this was significantly associated factor. Accordingly, pregnant mothers with history of circumcision were 4.8 times more likely infected than those without circumcision \{AOR (4.4), 95\% CI $(1.59,12.15)$; p-value (0.004)\}. This finding is supported by a study in Sana, Yemen which stated circumcision had significant association with the infection [34].
The antibody test for HIV revealed that the prevalence of HIV in the study area among pregnant mothers attending ANC service was found to be 17 (5.1\%). The finding is in line with Ethiopia 2005 reported HIV prevalence of $5.3 \%$ but lower than the reported prevalence of $6.6 \%$ in Bahir Dar Ethiopia 2014 [42,43]. Similarly, out of the seventeen HIV positive pregnant mothers, $8(47.1 \%)$ had infected with HBV. Hence the prevalence of HIV/HBV co-infection in this study (47.1\%) was higher than the study done during 2011 in rural hospital, Ethiopia (0.6\%), in Addis Ababa Ethiopia (14.3\%), and in Bahir Dar Ethiopia (19\%) $[43,44]$. The observed higher prevalence of HIV/HBV co-infection in the current study can be justified by the fact that in areas where HBV infection is either endemic or intermediate to high (i.e. $>8 \%$ which is in agreement with $8.4 \%$ prevalence in this study), the prevalence rate of $\mathrm{HIV} / \mathrm{HBV}$ co-infection is recorded as high as $10 \%$ to $20 \%$, even the rate can be as high as $20-25 \%$ in countries where the viruses are highly endemic $[45,46]$.

In multivariate analysis, having HIV comorbidity increased the risk of having HBV infection more than four times as compared with those who are HIV negative AOR (4.1), 95\% CI (1.13, 15.09); p-value (0.032)\}. There are other reports that documented similar findings in Ethiopia [20]. The major justification for the observed association and simultaneous appearance of HBV and HIV might be explained by their nature of sharing similar mode of transmission. In contrary, the study in Dessei reported no significant association between sero-prevalence of HBV and HIV status of the women [19].

Although significant association was not observed in multivariate analysis, pregnant mothers who had one or more history of abortion and those who had experienced multiple sexual practice had higher infection rate and were associated in the crude odd ratio. This finding is 
Citation: Mekonnen R, Admasu D, Belete M (2018) Sero-Prevalence of Hepatitis B Virus and Associated Factors Among Pregnant Mothers Attending Antenatal Care in Public Health Facilities, Dire Dawa. J Med Microb Diagn 7: 281. doi:10.4172/2161-0703.1000281

Page 7 of 8

in contrary to previous studies in Bishoftu and Dessei Referral hospital which documented a reverse phenomenon. But our finding is similar in the case of a study at Shashemene that having multiple sex partners was not significantly associated with HBV infection [35].

\section{Conclusion}

The sero-prevalence of HBV infection among pregnant mothers in the study area was comparatively higher, which indicates hyperendemicity and high nature of the infection.

On multivariate analysis, being single pregnant mothers, having nose/ear piercing, history of circumcision, blood transfusion, and HIV co-infection had statistically significant association with positivity of HBV infection. This suggests that being single pregnant mothers, having had invasive procedures like nose/ear piercing and circumcision, history of blood transfusion and or donation as well as HIV co-infection predispose pregnant women for $\mathrm{HBV}$ infection compared with the reverse phenomena.

Although association was not significant when adjusted with other variables, in the crude analysis pregnant mothers who experienced multiple sexual practice, who had tattooing, history of previous surgery and abortion showed significant association with sero-positivity of HBsAg.

\section{Recommendations}

- To halt spread of these viruses, increasing awareness on modes of transmission should be considered.

- Awareness should be created among parents to avoid sharing of needles for invasive procedures like nose or ear piercing.

- Safety procedures should be followed during blood transfusion at all health facilities.

- Screening all pregnant women for HBV should be made as part of routine antenatal care service in the study area.

- Postpartum HBV immunization of pregnant mothers should be undertaken.

- Interventions should be targeted on reduction of female circumcision by city administrator, regional health bureau and other stakeholders.

- Since higher prevalence of HBV is observed in pregnant mothers, further community-based study should be conducted to determine the exact prevalence of HBV among the general population in the study area.

\section{Ethical Approval}

Ethical clearance was obtained from Social and Public Health Research Ethics Review Committee, College of Medicine and Health Sciences, Dire Dawa University. All processes started after safe and sound written permission obtained from Dire Dawa Regional Health Bureau, head of the health facilities and participated pregnant mothers.

\section{Acknowledgement}

The authors are grateful to the study participants, data collectors and health facility authorities. Robel Mekonnen was major contributor designed the study, participated in the data collection, analysis, interpretation and write-up, drafted the manuscript and critically revised the manuscript. Dawit Admasu and Meseret Belete participated in the study design, interpretation and write-up. All authors read and approved the final manuscript. This study was supported by Dire Dawa University, Ethiopia.

\section{References}

1. Adabara NU, Ajala OO, Momohjimoh A, Hashimu Z, Agabi AYV (2012) Prevalence of Hepatitis B virus among women attending antenatal clinic in the General Hospital, Minna, Niger State. Shiraz E Med J 13: 28-32.

2. Shepard CW, Simard EP, Finelli L, Fiore AE, Bell BP (2006) Hepatitis B virus infection: Epidemiology and vaccination. Epidemiol Rev 28: 112-125.

3. Alberti A, Chemeillo L, Benuegnu LP (1999) Natural history of Hepatitis C. J Hepatol 1: 17-24.
4. Mast EE, Margolis HS, Fiore AE, Brink EW, Goldstein ST, et al. (2005) A comprehensive immunization strategy to eliminate transmission of Hepatitis $B$ virus infection in the United States: Recommendations of the Advisory Committee on Immunization Practices (ACIP) Part 1: Immunization of infants, children, and adolescents. MMWR Recomm Rep 54: 1-31.

5. World Health Organization (2016) Emergencies preparedness, response: Hepatitis. World Health Organization, 2016. Global policy report on the prevention and control of viral hepatitis in WHO member states.

6. Khan S, Attaullah S (2011) Share of Afghanistan populace in Hepatitis B and Hepatitis C infection's pool. Virol Journal 8: 216.

7. Adibi P, Akbari L, Kahangi LS, Abdi $F$ (2012) Health-State utilities in liver cirrhosis: A cross-sectional study. Int J Prev Med 3: S94-S101.

8. Verma R, Khanna P, Prinja S, Rajput M, Chawla S, et al. (2011) Hepatitis B vaccine in national immunization schedule: A preventive step in India. Hum Vaccin 7: 1387-1388.

9. World Health Organization (2015) Hepatitis B fact sheet No: 204. Geneva 2: 1.

10. Schweitzer A, Horn J, Mikolajczyk RT, Krause G, Ott JJ (2015) Estimations of worldwide prevalence of chronic Hepatitis $B$ virus infection: A systematic review of data published between 1965 and 2013. Lancet 386: 1546-1555.

11. Zampino R, Boemio A, Sagnelli C, Alessio L, Adinolfi LE, et al. (2015) Hepatitis $B$ virus burden in developing countries. World J Gastroenterol 21: 11941-11953.

12. GBD 2013 Mortality and Causes of Death Collaborators (2015) Global, regional and national age-sex specific all-cause and cause-specific mortality for 240 causes of death, 1990-2013: A systematic analysis for the global burden of disease study 2013. Lancet 385: 117-171.

13. Gasim GI, Murad IA, Adam I (2013) Hepatitis B and C virus infections among pregnant women in Arab and African countries. J Infect Dev Ctries 7: 566-578.

14. Shukla S, Mehta G, Jais M, Singh A (2011) A prospective study on acute vira hepatitis in pregnancy: Seroprevalence and fetomaternal outcome of 100 cases. J Biosci Tech 2: 279-286.

15. World Health Organization (2008) Hepatitis B. World Health Organization 2: 1.

16. Sookoian S (2006) Liver disease during pregnancy: Acute viral hepatitis. Ann Hepatol 5: 231-236.

17. WHO (2013) Global policy report on the prevention and control of viral hepatitis p: 536.

18. Semaw A, Awet H, Yohannes M (2015) Sero-prevalence of Hepatitis B surface antigen and associated factors among pregnant mothers attending antenatal care service, Mekelle, Ethiopia: Evidence from institutional based quantitative cross-sectional study. World Academy of Science, Engineering and Technology: Med Health Sci 2: 9 .

19. Baye G, Mohammed S, Abate A (2014) Sero-prevalence of HBV and HCV infections among pregnant women attending antenatal care clinic at Dessie Referral Hospital, Ethiopia. Adv Life Sci Health 1: 109-120.

20. Desalegn Z, Wassie L, Beyene HB, Mihret A, Ebstie YA (2016) Hepatitis B and human immunodeficiency virus co-infection among pregnant women in resource-limited high endemic setting, Addis Ababa, Ethiopia: Implications for prevention and control measures. Eur J Med Res 21: 16.

21. Umare A, Seyoum B, Gobena T, Haile-Mariyam T (2016) Hepatitis B Virus infections and associated factors among pregnant women attending antenatal care clinic at Deder Hospital, Eastern Ethiopia. PLOS One 11: e0166936.

22. Federal Democratic Republic of Ethiopia (2010) National expanded programme on immunization comprehensive multi-year plan 2011-2015. Addis Ababa: Fedral Ministry of Health 2: 1 .

23. CSA (2007) Central Statistics Agency, Ethiopia.

24. http://www.ethiopia.gov.et/statediredawa.

25. https://en.m.wikipedia.org.

26. Lee C, Gong Y, Brok J, Boxall EH, Gluud C (2006) Effect of Hepatitis B immunization in newborn infants of mothers positive for Hepatitis B surface antigen: Systematic review and meta-analysis. BMJ 332: 328-336.

27. Hou J, Liu Z, Gu F (2005) Epidemiology and prevention of Hepatitis B virus infection. Int J Med Sci 2: 50-57.

28. Alter MJ (2003) Epidemiology of Hepatitis B in Europe and worldwide. J Hepatol 39: S64-S69. 
29. Metaferia Y, Dessie W, Ali I, Amsalu A (2016) Seroprevalence and associated risk factors of Hepatitis $B$ virus among pregnant women in southern Ethiopia: $A$ hospital-based cross-sectional study. Epidemiol Health 38: e2016027.

30. Fomulu NJ, Morfaw FL, Torimiro JN, Nana P, Koh MV, et al. (2013) Prevalence, correlates and pattern of Hepatitis $B$ among antenatal clinic attenders in Yaounde-Cameroon: Is perinatal transmission of HBV neglected in Cameroon? BMC Pregnancy Childbirth 13: 1-10.

31. Mac Lean B, Hess RF, Bonvillain E, Kamate J, Dao D, et al. (2012) Seroprevalence of hepatitis B surface antigen among pregnant women attending the Hospital for Women \& Children in Koutiala, Mali. S Afr Med J 102: $47-49$.

32. Pennap GR, Osanga ET, Ubam A (2011) Seroprevalence of Hepatitis B surface antigen among pregnant women attending antenatal clinic in Federal Medical Center, Keffi, Nigeria. Res J Med Sci 5: 80-82.

33. Ndams IS, Joshua IA, Luka SA, Sadiq HO (2008) Epidemiology of Hepatitis B infection among pregnant women in Minna, Nigeria. Sci world J 3: 3.

34. Murad EA, Babiker SM, Gasim GI, Rayis DA, Adam I (2013) Epidemiology of Hepatitis B and Hepatitis C virus infections in pregnant women in Sana'a Yemen. BMC pregnancy childbirth 13: 37.

35. Ministry of Health Uganda (2012) Uganda AIDS Indicator Survey MOH.

36. Erena AN, Tefera TB (2011) Prevalence of Hepatitis B surface antigen (HBsAg) among visitors of Shashemene General Hospital voluntary counseling and testing center. BMC Research 2: 1.

37. Desalegn Z, Mihret A, Beyene HB, Yilma M, Seid Y, et al. (2016) Survey of Hepatitis $B$ virus infection and risk factors among pregnant women at public hospital in Ethiopia. Int J Biomed Res 7: 450-456.
38. Zahran KM, Badary MS, Agban MN, Abdel Aziz NH (2010) Pattern of HBV Infection among pregnant women and their newborns at the Women Health Center of Asssiut University, Upper Egypt. Int J Gynaecol Obstet 111: 171-174.

39. Taseer IH, Ishaq F, Hussain L, Safdar S, Mirbahar AM, et al. (2010) Frequency of anti-HCV, HBsAg and related risk factors in pregnant women at Nishtar Hospital, Multan. J Ayub Med Coll Abbottabad 22: 1.

40. Yakasai IA, Ayyuba R, Abubakar IS, Ibrahim SA (2012) Sero-prevalence of Hepatitis $B$ virus infection and its risk factors among pregnant women attending antenatal clinic at Aminu Kano Teaching Hospital, Kano, Nigeria. J Basic Clin Reprod Sci 1: 49-55.

41. Mortada ES, Mohamed MF, Hamdi MSED, Ehab M, Khamiss SS, et al. (2013) Prevalence of Hepatitis $B$ virus infection among Egyptian pregnant women: A single center study. Int J Trop Dis Health 3: 157-168.

42. Federal Ministry of Health/National HIVIAIDS Prevention and Control Offices (2005) Aids in Ethiopia Sixth Report, Ethiopia.

43. Zenebe Y, Mulu W, Yimer M, Abera B (2014) Sero-prevalence and risk factors of hepatitis $B$ virus and human immunodeficiency virus infection among pregnant women in Bahir Dar city, Northwest Ethiopia: A cross sectional study BMC Infect Dis 14: 118.

44. Ramos JM, Toro C, Reyes F, Amor A, Gutiérrez F (2011) Seroprevalence of HIV-1, HBV, HTLV-1 and Treponema pallidum among pregnant women in rural hospital in Southern Ethiopia. J Clin Virol 51: 83-85.

45. Muriuki BM, Gicheru MM, Wachira D, Nyamache AK, Khamadi SA (2013) Prevalence of Hepatitis B and C viral co-infections among HIV-1 infected individuals in Nairobi, Kenya. BMC Res Notes 6: 363.

46. Kew MC (2012) Hepatitis B virus/human immunodeficiency virus co-infection and its hepatocarcinogenic potential in sub-saharan black Africans. Hepat Mon 12: e7876. 